\title{
INABILITY TO DEMONSTRATE A PLATELET REDUCING SUB- STANCE IN AN ACETONE EXTRACT OF THE SPL.EEN FROM PATIENTS WITH IDIOPATHIC THROMBOCYTOPENIC PURPURA ${ }^{1}$
}

\author{
BY FREDERICK J. POHLE AND OVID O. MEYER \\ (From the Department of Medicine, University of Wisconsin Medical School, Madison)
}

(Received for publication April 17, 1939)

It is well established that some relationship exists between the spleen and the number of platelets in the circulating blood. Splenectomy performed on patients with chronic idiopathic thrombocytopenic purpura frequently results in a clinical and hematological cure. Recent investigations $(1,2,3)$ suggest that the spleen of patients with this disease contains a substance capable of reducing the number of blood platelets in certain laboratory animals. This material, obtained by acetone extraction, has been called thrombocytopen (3). It was reported that the intravenous injection of thrombocytopen into a normal rabbit reduced the platelet value as much as 90 per cent. Such observations, if confirmed, would be an important contribution to a better understanding of certain purpuric conditions. The purpose of the present investigation was to confirm these recent studies.

\section{METHODS}

The material for this study was obtained from the spleens of three patients with typical chronic idiopathic thrombocytopenic purpura. An abstract of the history, physical examination, and laboratory findings in these cases will be given later in this communication.

The method used for the preparation of the acetone extract of each spleen was essentially the same as that described by Troland and Lee (3). In each instance the spleen was taken directly from the operating rooms, finely ground in a food chopper, and placed in five volumes of acetone U.S.P. The flask was kept in the ice box at $5^{\circ}$ C. and shaken for 5 minutes daily. After an interval of from 34 to 76 days the light-orange supernatant extract was filtered and the acetone removed from the filtrate by distillation. A yel-

1 This study was aided in part by a grant from the Wisconsin Alumni Research Foundation. low-brown, fatty, sticky residue remained on the walls of the flask. In each case $100 \mathrm{cc}$. of distilled water was added to the distilling flask, shaken vigorously for 10 minutes, and filtered through one thickness of coarse filter paper. The final preparations were cloudy. Each of the three splenic extracts was used within 48 hours after its preparation.

White male rabbits, approximately 6 months of age, weighing from 2.5 to 4 kilograms, were used as the test animal. A new rabbit was used for every injection. The injections were made into the marginal veins of the ear.

Blood platelet determinations were made with the aid of an isotonic diluting fluid by a method previously described (4). The counts on the purpuric patients were made on capillary blood obtained from the ear; the counts on the rabbits were made on blood obtained from the ear veins. Previous studies have indicated that blood platelet determinations by this method, when performed by an experienced individual, include an approximate technical error of from +4 per cent to -4 per cent.

\section{OBSERVATIONS}

Case I. This patient, a white schoolgirl, 16 years of age, was admitted to the hospital with a chief complaint of protracted menorrhagia. The patient had suffered from menorrhagia, bleeding from the gums, frequent epistaxis, and easy bruising for 10 months. During this period 6, $500 \mathrm{cc}$. blood transfusions had been given for anemia. The past history was not pertinent, and there was no family history of any hemorrhagic disorder.

Physical examination upon admission revealed a well developed, well nourished girl with marked pallor. There was bleeding from the gums and vagina. There were numerous petechiae and ecchymotic areas, both old and recent, over the 
entire body. The heart and lungs were normal. The blood pressure was $136 / 88$. The spleen edge was barely palpable below the left costal margin. Aside from the uterine bleeding the pelvic examination was not significant. vealed nothing abnormal. The blood Wassermann test was negative. X-ray studies of the lungs, paranasal sinuses, and teeth were normal.

The patient was observed on the medical service for 6 weeks without change in the clinical or

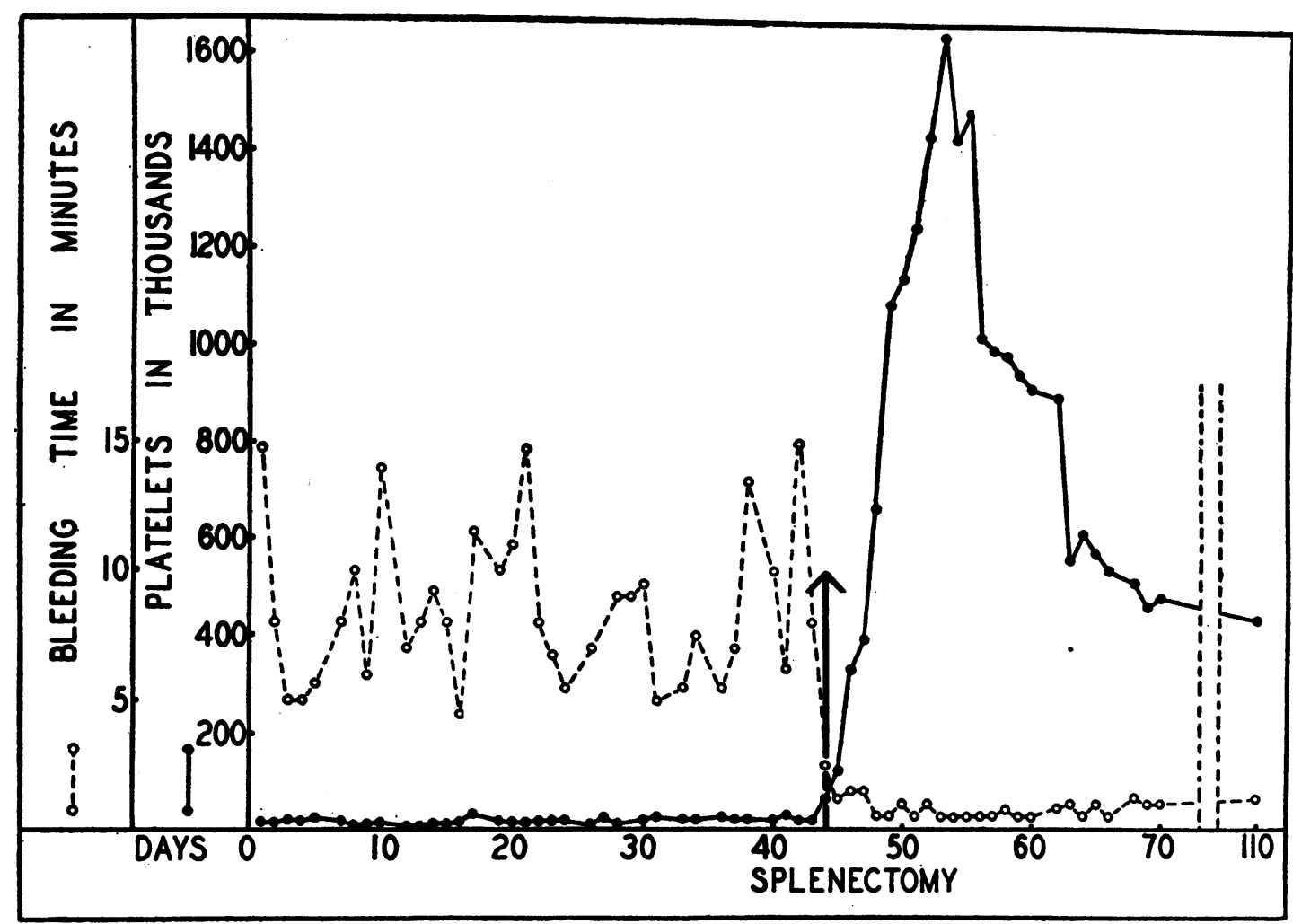

Fig. 1. Effect of Splenectomy on the Bloop Platelet Count and Bleeding Time in an Individual (Case I) with Idiopathic Thrombocytopenic Purpura

On admission to the hospital the hemoglobin was 6.36 grams per $100 \mathrm{cc}$. and the erythrocyte count was $2,380,000$ per cu. $\mathrm{mm}$. The leukocyte count was 6,700 per $\mathrm{cu}$. $\mathrm{mm}$. and the differential count was within normal limits. The red blood cells showed moderate variation in size and shape. The blood platelet count was 23,000 per cu. mm. There was no retraction of the clot in 24 hours. The bleeding time (Duke's method) was 15 minutes and the coagulation time, determined by placing $2 \mathrm{cc}$. of venous blood in a $100 \times 13 \mathrm{~mm}$. test tube kept at $37.5^{\circ} \mathrm{C}$., was 8 minutes. The tourniquet test was strongly positive. The plasma prothrombin (Quick's method) was 100 per cent. The blood cevitamic acid was $1.31 \mathrm{mgm}$. per $100 \mathrm{cc}$. Urine and stool examinations re- laboratory status. During this time she received 7,500 cc. blood transfusions. After this period a splenectomy was done. The blood platelet count showed a significant increase 4 hours later and all of the hemorrhagic manifestations ceased. There has been no recurrence of abnormal bleeding. Figure 1 shows the blood platelet counts and bleeding times on this patient during the period of hospitalization. The hemoglobin and red blood cells rapidly rose to normal with iron therapy.

An extract was prepared from the spleen obtained from this case in the manner previously described. The spleen weighed 265 grams. An interval of 59 days was allowed for the extraction. A portion of this extract (Number 1) was ad- 
ministered intravenously to each of three rabbits. and the effect on the blood platelet counts was observed. The results are presented in Table I.

TABLE I

Effect of intravenous injection of splenic extract Number 1 on the blood platelet counts of three rabbits

\begin{tabular}{c|c|c|c}
\hline \hline & \multicolumn{3}{|c}{ Platelets } \\
\cline { 2 - 4 } Time & $\begin{array}{c}\text { Rabbit } \\
\text { number 1 } \\
\text { (received } \\
15 \text { cc.) }\end{array}$ & $\begin{array}{c}\text { Rabbit } \\
\text { number 2 } \\
\text { (received } \\
\text { 23 cc.) }\end{array}$ & $\begin{array}{c}\text { Rabbit } \\
\text { number 3 } \\
\text { (received } \\
50 \text { cc.) }\end{array}$ \\
\hline hours & per cu. mm. & per cu. mm. & per cu. mm. \\
Before injection & & & \\
48 & 415,000 & 397,000 & 529,000 \\
24 & 396,000 & 420,000 & 530,000 \\
1 & 400,000 & 389,000 & 558,000 \\
After injection & & & \\
1 & 390,000 & 367,000 & 522,000 \\
3 & 374,000 & 472,000 & \\
5 & 387,000 & 430,000 & 550,000 \\
7 & 402,000 & & 546,000 \\
10 & 425,000 & 406,000 & 537,000 \\
20 & 375,000 & 359,000 & 518,000 \\
30 & 416,000 & 408,000 & 493,000 \\
48 & 387,000 & 397,000 & 505,000 \\
72 & 409,000 & 414,000 & \\
\hline
\end{tabular}

Case II. This patient, a 20-year-old white housewife, was admitted to the hospital because of bleeding from the gums. The patient stated that she had bruised easily for several years. However, during the past four months she had had repeated severe epistaxis, bleeding from the gums, menorrhagia, and numerous petechiae and ecchymoses over the skin and mucous membranes. Three weeks prior to admission she had had prolonged hemorrhage following two dental extractions. Three blood transfusions were required to keep the hemoglobin from becoming dangerously low. Weakness and ease of fatigue became quite severe. The remainder of the history was irrelevant and there was no hemorrhagic disorder in other members of her family.

On physical examination the patient exhibited marked pallor and lethargy. There was bleeding from the gums and vagina, fresh retinal hemorrhages bilaterally, numerous petechiae over all extremities and in the mouth, splenomegaly and moderate cervical lymph node enlargement. The remainder of the examination revealed nothing abnormal.

On admission to the hospital the hemoglobin was 5.5 grams per $100 \mathrm{cc}$., and the erythrocytes numbered 1,920,000 per cu. $\mathrm{mm}$. The leukocyte count was 9,950 per cu. mm., and the differential count was normal. The red blood cells showed microcytosis and a few nucleated forms. Careful examination of the blood smear showed a marked diminution in the number of blood platelets. There was no retraction of the blood clot in 24 hours. The bleeding time was 38 minutes and the blood coagulation time determined by the capillary tube method was 3 minutes. The tourniquet test was positive. The plasma prothrombin (Quick's method) was 100 per cent. The blood cevitamic acid was $0.82 \mathrm{mgm}$. per $100 \mathrm{cc}$. Urine and stool examinations revealed nothing abnormal. The blood Wassermann test was negative. Chest and dental $x$-rays were within normal limits.

There was no essential change in this case during the next three weeks under medical observation. Five $400 \mathrm{cc}$. blood transfusions were given during this interval without permanent effect upon the bleeding tendency. The method used for the blood platelet counts during this time was not reliable. However, the platelets were greatly reduced on repeated examinations of the blood smear and the bleeding time showed values from 10 minutes to 2 hours. A splenectomy was performed, and the patient was subsequently observed in the hospital for 10 weeks. Unlike Case I, the hemorrhagic manifestations persisted during this time although they were less severe. The blood platelets never exceeded 35,000 per cu. mm. Seven $400 \mathrm{cc}$. blood transfusions were given during this postoperative period, and at the time of discharge the hemoglobin was 14.3 grams per $100 \mathrm{cc}$., and the red blood cell count was $4,540,000$ per cu. $\mathrm{mm}$.

This patient has been seen on two occasions in the outpatient department since discharge from the hospital. Four months after splenectomy the blood platelet count was 198,000 per $\mathrm{cu}$. mm. and 7 months after splenectomy the count was 452,000 per cu. mm. The patient has been free of any severe hemorrhages since her discharge from the hospital.

The spleen obtained from this case weighed 310 grams. Immediately after its removal it was ground and placed in five volumes of acetone and an extract was prepared as before. In this 
instance 76 days were allowed for extraction. A portion of this extract (Number 2) was injected intravenously into each of three rabbits and the effect on the number of blood platelets observed. The data are given in Table II.

TABLE II

Effect of intravenous injection of splenic extract Number 2 on the blood platelet counts of three rabbits

\begin{tabular}{c|c|c|c}
\hline & \multicolumn{3}{|c}{ Platelets } \\
\cline { 2 - 4 } Time & $\begin{array}{c}\text { Rabbit } \\
\text { number } \\
\text { (received } \\
15 \text { cc.) }\end{array}$ & $\begin{array}{c}\text { Rabbit } \\
\text { number } 5 \\
\text { (received } \\
25 \text { cc.) }\end{array}$ & $\begin{array}{c}\text { Rabbit } \\
\text { number } 6 \\
\text { (received } \\
50 \text { cc.) }\end{array}$ \\
\hline hours & per cu. mm. & per cu. mm. & per cu. mm. \\
Before injection & & 433,000 & 502,000 \\
48 & 432,000 & 502,000 & 504,000 \\
24 & 485,000 & 429,000 & 557,000 \\
1 & & & \\
After injection & 471,000 & 486,000 & 486,000 \\
1 & 505,000 & 518,000 & 554,000 \\
3 & 437,000 & 427,000 & 466,000 \\
6 & 468,000 & 478,000 & 430,000 \\
10 & 499,000 & 503,000 & 558,000 \\
20 & 538,000 & & \\
24 & 546,000 & 460,000 & 501,000 \\
48 & 462,000 & 472,000 & 514,000 \\
72 & & & \\
\hline
\end{tabular}

Case III. This patient, a white boy, age 10 years, was admitted to the hospital with a chief complaint of epistaxis and easy bruising. The patient was in good health until 4 weeks before entry when he first had a severe epistaxis. Purpura became evident over the entire body and on the day previous to admission the patient had 4 emeses of bright red blood. There were no recent infections, and there was no history of an abnormal bleeding tendency in any other member of the family.

Physical examination showed a well developed, well nourished, pale boy with petechiae and purpuric areas over the entire body. The tonsils were hypertrophic and infected. The remainder of the physical examination was essentially normal. The spleen was not palpable.

Laboratory studies on admission showed a hemoglobin of 8.5 grams per $100 \mathrm{cc}$., an erythrocyte count of $3,300,000$ per cu. mm., and a leukocyte count of 9,000 per $\mathrm{cu}$. $\mathrm{mm}$. The blood smear revealed a normal differential count and changes in the red blood cells consistent with hypochromic anemia. The blood platelet count was 13,000 per cu. mm., and there was no retraction of the blood clot in 24 hours. The bleeding time was 12 minutes, and the venous blood coagulation was 7 minutes. The tourniquet test was positive. The blood cevitamic acid was $1.4 \mathrm{mgm}$. per $100 \mathrm{cc}$. Urine and stool examinations were normal. The blood Wassermann test was negative. X-rays of the lungs, sinuses, teeth, and long bones were normal.

The patient was treated medically in the hospital for 6 months without improvement in the bleeding tendency. The tonsils, and 2 teeth with apical abscesses, were removed with resultant dangerous hemorrhage. During this protracted preoperative period a total of 9,250 cc. blood transfusions was given. This patient also received two courses of $\mathrm{x}$-ray therapy to the splenic area. One hundred $r$ (in air) were given over the anterior and posterior spleen on consecutive days up to a total of $400 r$ over each area. Ten weeks later $200 r$ (in air) were given over the anterior and posterior spleen on consecutive days up to a total of $800 r$ over each area. Customary deep $\mathrm{x}$-ray therapy technique was used (half value layer in $\mathrm{Cu}=1.0 \mathrm{~mm}$.). Repeated blood platelet counts during this time never showed a value of over 58,000 per cu. mm., and the bleeding time was persistently prolonged. After this period a splenectomy was performed and the hemorrhages ceased immediately. The response of the blood platelets to splenectomy was very similar to that in Case $I$ as shown in Figure 1. With the cessation of bleeding the anemia rapidly improved. An outpatient visit 3 months after surgery established that there had been no recurrence of abnormal bleeding. The blood platelet count at this time was 244,000 per cu. mm.

An acetone extract was prepared from this spleen (weight 70 grams), in the same manner as previously described. In this instance 34 days were allowed for extraction. A portion of this splenic extract (Number 3 ) was again administered intravenously to each of three rabbits and the effect on blood platelet values noted. The results are shown in Table III.

There were no local or general reactions noted in any of the rabbits as a result of the intravenous injection of the splenic extracts. The animals were carefully watched following the injections but no hemorrhagic manifestations were 
TABLE III

Effect of intravenous injection of splenic extract Number 3 on the blood platelet counts of three rabbits

\begin{tabular}{c|c|c|c}
\hline \hline & \multicolumn{3}{|c}{ Platelets } \\
\cline { 2 - 4 } Time & $\begin{array}{c}\text { Rabbit } \\
\text { number } \\
\text { (received } \\
\text { 7cc.) }\end{array}$ & $\begin{array}{c}\text { Rabbit } \\
\text { number 8 } \\
\text { (received } \\
\text { 24 cc.) }\end{array}$ & $\begin{array}{c}\text { Rabbit } \\
\text { number } \\
\text { (received } \\
\text { (42 cc.) }\end{array}$ \\
\cline { 2 - 4 } hours & per cu. mm. & per cu. mm. & per cu. mm. \\
Before injection & 547,000 & & \\
48 & 553,000 & 415,000 & 407,000 \\
24 & 600,000 & 368,000 & 385,000 \\
2 & 565,000 & 395,000 & 370,000 \\
1 & & & \\
After injection & 582,000 & 387,000 & 339,000 \\
1 & 599,000 & 408,000 & 364,000 \\
2 & 615,000 & 404,000 & 341,000 \\
4 & 569,000 & 455,000 & 359,000 \\
8 & 578,000 & 381,000 & 370,000 \\
12 & 626,000 & 400,000 & 343,000 \\
20 & 588,000 & 395,000 & 351,000 \\
48 & & & \\
\hline
\end{tabular}

observed. Abnormal bleeding never occurred after the incisions of the ear veins necessary for the numerous blood platelet counts.

The gross and microscopic appearances of the spleens were not outstanding. In every case the follicles were quite hyperplastic and the sinusoids were dilated and filled with phagocytes containing blood pigment. The spleen obtained from Case III showed no fibrosis as a result of the two courses of $\mathrm{x}$-ray therapy.

\section{CONCLUSION}

The present investigations do not confirm previous reports that an acetone extract of the spleen from individuals with chronic idiopathic thrombocytopenic purpura contains a substance capable of reducing the number of blood platelets in rabbits.

\section{BIBLIOGRAPHY}

1. Torrioli, Mario, and Puddu, Vittorio, Recent studies on pathogenesis of Werlhof's disease. J. A. M. A., 1938, 111, 1455.

2. Troland, Charles E., and Lee, Ferdinand C., A preliminary report on a platelet-reducing substance in the spleen of thrombocytopenic purpura. Bull. Johns Hopkins Hosp., 1938, 62, 85.

3. Troland, Charles E., and Lee, Ferdinand C., Thrombocytopen; substance in extract from spleen of patients with idiopathic thrombocytopenic purpura that reduces number of blood platelets. J. A. M. A., 1938, 111, 221.

4. Pohle, Frederick J., The blood platelet count in relation to the menstrual cycle in normal women. Am. J. Med. Sc., 1939, 197, 40. 